\title{
Neoliberalismo petrolero en la política económica exterior de México ${ }^{1}$ \\ Oil Neoliberalism in Mexico's Foreign Economic Policy
}

\author{
Einer David, Tah-Ayala ${ }^{2}$ \\ Universidad del Mar, México \\ https://orcid.org/0000-0001-8293-9852
}

\section{RESUMEN}

El objetivo del artículo es analizar la importancia que ha tenido el neoliberalismo, en la industria petrolera, como política de desarrollo para México, y elemento comercial y soberano para el país, desde los resultados comparados con la política de Industrialización por Sustitución de importaciones aplicada en los cuarenta años previos a su aplicación. Para este análisis fueron comparadas la cantidad de reservas, la producción, las exportaciones e importación de crudo y productos derivados, en cantidad, ingresos y gastos, así como el precio internacional de petróleo y las políticas alternas que propone el nuevo gobierno de Andrés Manuel López Obrador. Como resultado, el artículo comprobó que el neoliberalismo incrementó la producción y las reservas y, en primera instancia, también los ingresos, pero con el paso del tiempo también aumentaron las importaciones de productos refinados y químicos y disminuyeron los ingresos haciendo a la empresa, junto con las reformas estructurales de 2013, una especie de clúster petrolero. Por esa razón, el presidente López Obrador propuso cambiar el sistema petrolero y regresar a la política de protección del recurso como elemento soberano, aunque los analistas no concuerdan con las primeras acciones de su gobierno.

Palabras Clave: Exportación, Importación, Neoliberalismo, Petróleo mexicano, Política exterior.

\section{ABSTRACT}

The objective of the article is to analyze the importance that neoliberalism has had as a development policy for Mexico and a commercial and sovereign element for the country and its oil industry, from the results compared with the Import Substitution Industrialization policy applied in the forty years prior to its application. For this analysis, the amount of reserves, production, exports and imports of crude and derived products, in quantity, income and expenses, as well as the international oil price and the alternative policies proposed by the government of Andrés Manuel López Obrador were compared. As a result, the paper found that neoliberalism increased production and reserves and -in the first instance- also revenues, but over time also increased imports of refined and chemical products and decreased revenues making the company, beside with the structural reforms of 2013, a kind of oil cluster. For that reason, President López Obrador proposed changing the oil system and returning to the resource protection policy as a sovereign element, although analysts do not agree with the first actions of his government.

Keywords: Export, Foreign Policy, Import, Mexican Oil, Neoliberalism.

Recibido: 10 de Enero 2019 - Aceptado: 09 de Abril 2019

Cómo referenciar este artículo:

Tah-Ayala, E. D. (2019). Neoliberalismo petrolero en la política económica. Revista Política, Globalidad y Ciudadanía, 110-133. Recuperado de http://revpoliticas.uanl.mx/index.php/RPGyC/article/view/124

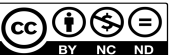

1 Artículo de investigación derivado del proyecto de investigación: El papel de la identidad en los procesos de desarrollo global financiado por la Universidad del Mar.

2 Doctor en Estudios del Desarrollo Global por Universidad Autónoma de Baja California Campus Tijuana. Profesor-Investigador de tiempo completo, Universidad del Mar, Campus Huatulco. Correo: einer.david@huatulco.umar.mx.

Revista Política, Globalidad y Ciudadanía, Vol. 5 No. 10, Julio - Diciembre 2019, Universidad Autónoma de Nuevo León, Monterrey, México, ISSN 2395-8448. 110-133. http://revpoliticas.uanl.mx/index.php/RPGyC/article/view/124 


\section{1.- INTRODUCCIÓN}

El petróleo en México ha pasado por diferentes etapas dependiendo de la época en la que atravesaba el país. Tras casi 150 años de historia, el petróleo sufrió diversas adaptaciones a la economía nacional haciéndolo parte medular de la industria energética y, con ello, parte de la identidad nacional que lo constituyó como el medio de ingreso más importante del país. El sexenio de Miguel de la Madrid Hurtado fue decisivo para la historia mexicana al significar la entrada del país al mercado económico global y, con esto, del petróleo, a pesar de que el discurso continuó siendo a favor de la protección del mineral como propiedad de la nación.

En ese sentido, el siguiente artículo analiza las características petroleras del comercio internacional del país como las importaciones y exportaciones, las ganancias y pérdidas por estos conceptos y las reservas y explotación de éstas desde 1911 hasta septiembre de 2019, tomando en cuenta los periodos políticos y tratando de aterrizar el comportamiento del petróleo mexicano con los procesos coyunturales del escenario internacional. De esa manera, el crecimiento, aumento de reservas y producción; el incremento de ingresos - y gastos por importación de productos refinados - ocasiona que sea necesario replantear los proyectos sobre la industria petrolera nacional. Sin embargo, habría que cuestionarse si las propuestas y primeras acciones del gobierno lopezobradorista son significantes para cambiar el camino que ha tenido México desde 1986.

El problema a analizar en el escrito es que la política neoliberal ocasionó cambios es la forma en la que fueron desarrollados la explotación y exportación en la industria petrolera nacional, al tiempo que aumentaron las reservas, las exportaciones, pero también las importaciones. En ese sentido, la pregunta del problema es hasta qué grado la política neoliberal cambio la forma de desarrollar la industria petrolera del país, específicamente desde las exportaciones, las importaciones, las reservas y producción y tomando en cuenta el precio internacional del petróleo.

Si bien el neoliberalismo mostró problemas para resolver totalmente las necesidades y limitaciones de la industria petrolera mexicana, e incluso éstos incrementaron, la propuesta de regresar a la protección del recurso no suena descabellado. Sin embargo, la tendencia energética internacional es contraria a la propuesta mexicana, por lo que el país estaría explotando recursos que, según los estudios, tienen los días —o de manera más exacta, los años - contados.

\section{2.- FUNDAMENTO TEÓRICO}

\section{Evolución petrolera mexicana: antecedente al liberalismo petrolero}

Las expediciones para localizar petróleo en México datan de mediados del siglo XIX pero fue hasta 1863 que el primer poso fue perforado en Tepetitán, Macuspana estado de Tabasco. Al finalizar el siglo XIX, el gobierno de Porfirio Díaz otorgó protección legislativa para incentivar la inversión extranjeros y generar la infraestructura necesaria para la explotación y desarrollo de la industria petrolera (Garner, 2015).

Revista Política, Globalidad y Ciudadanía, Vol. 5 No. 10, Julio - Diciembre 2019, Universidad Autónoma de Nuevo León, Monterrey, México, ISSN 2395-8448. 110-133. http://revpoliticas.uanl.mx/index.php/RPGyC/article/view/124 
Según José López Portillo y Weber (1975, pág. 29), citado en Andrés Manuel López Obrador (2008), con la protección gubernamental a la inversión extranjera a diversos sectores del país, incluido el sector petrolero, la producción de crudo incrementó gradualmente.

En 1901, la producción era 10 mil barriles al año, mientras que en 1911 la producción ascendió a casi 12 millones 600 mil barriles al año, con exportaciones de más del $80 \%$ de la producción. El valor total de la producción en 1901 fue de 2 mil 69 pesos y aumentó a casi 4 millones 200 mil pesos en 1911 (pág. 18).

La producción petrolera solamente benefició a las empresas extranjeras pues éstos eran los únicos que contaban con capital, capacidad de gestión y experiencia tecnológica (Brown, 1993, pág. 8; y Meyer, 1981, pág. 50). De los 104 millones de pesos de inversión extranjera en 1911: 40 millones de pesos procedía de Estados Unidos; 57 millones 200 mil pesos, de Gran Bretaña y 6 millones 800 mil pesos, de Francia (Lajous, 2010, pág. 29). En 1911, México exportó 900 mil barriles al año, convirtiéndose en el cuarto productor mundial de petróleo (Uhthoff, 2010, pág. 9).

Con el estallido de la Revolución, Estados Unidos influyó en las decisiones gubernamentales al interior del país. Por este — entre otros factores - , la Revolución dio sentido a la Constitución de 1917 y abrió la posibilidad de una futura expropiación. Sin embargo, la Primera Guerra Mundial impidió que Estados Unidos tomara represalias por la promulgación de la Constitución de 1917. El descubrimiento de los pozos del Cerro Azul —en la zona de la Faja de Oro- hizo posible enfrentar los problemas bélicos incrementando la producción hasta alcanzar los 260 mil barriles diarios (Aguilera, 2015, pág. 21).

De 1911 a 1918, la producción casi llegó a 64 millones de barriles —valor de casi 90 millones de pesos - convirtiendo a México en el segundo exportador de petróleo a nivel mundial (Uhthoff, 2010, pág. 9).

Entre 1918 y 1921, dos tercios del petróleo nacional eran exportados y solamente el $6 \%$ era para consumo interno (Uhthoff, 2010, págs. 9-10). Para 1921, la producción petrolera superó los 193 millones de barriles de los cuales, 151 millones y medio (78 \%) fueron extraídos de la Faja de Oro.

Según la Secretaría del Patrimonio (1961), para 1924, la producción descendió a poco menos de 140 millones de barriles, de los cuales, la Faja de Oro aportó 39 millones (27 \%) (Como citó López Obrador, 2008, pág. 42). 
Gráfica 1. Producción anual de petróleo en Millones de Barriles, de 1900-1945

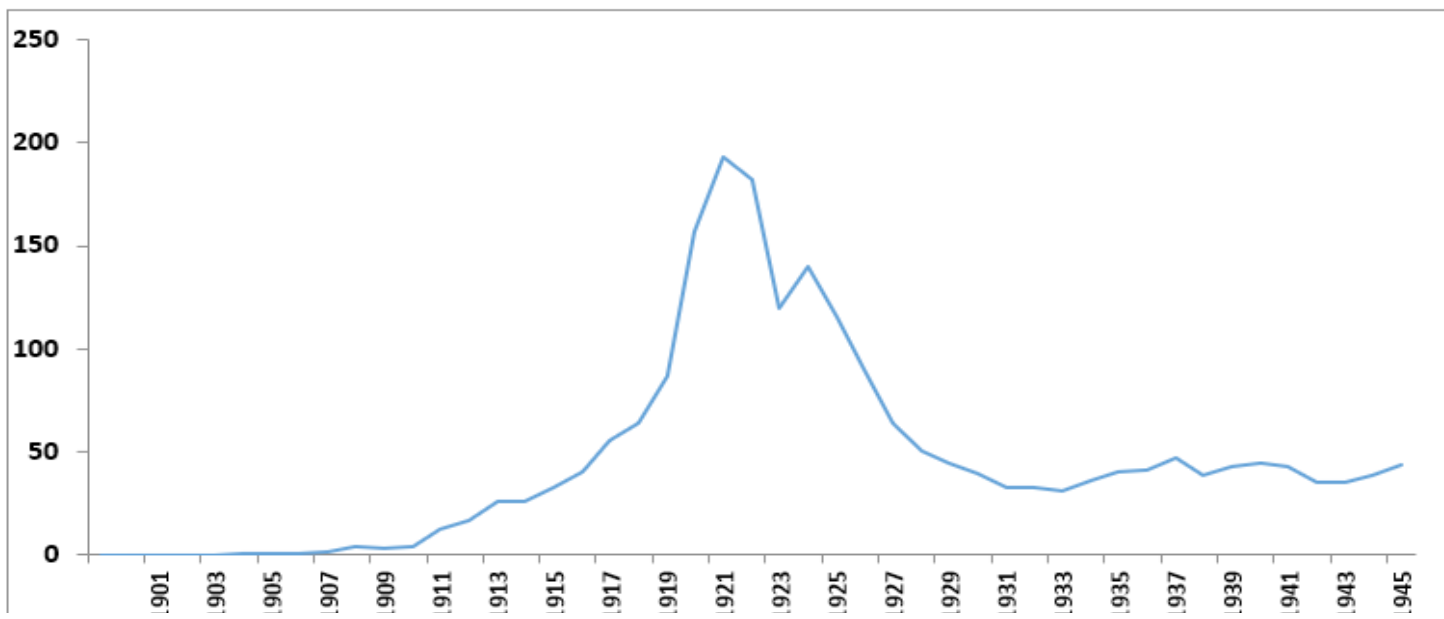

Fuente: Elaboración propia, con información de MéxicoMaxico.org.

A partir de 1924, la producción petrolera fue en descenso llegando a su punto más bajo en 1933 — descendió a 31 millones de barriles - . Con Lázaro Cárdenas, y el nacimiento de Petróleos de México A.C., la producción nacional ascendió. En 1934, la producción pasó de poco más de 36 millones a superar los 40 millones de barriles en 1935 — casi llegando a 47 millones en 1937- La expropiación generó un descenso, aunque mínimo, en la producción: en 1938, superó los 38 millones; en 1939, casi llegó a 43 millones y en 1940, apenas superó 44 millones de barriles. Con Manuel Ávila Camacho la producción mantuvo un ascenso hasta superar los 49 millones de barriles hasta 1946 (Aguilar, 2009).

\section{El petróleo mexicano en el escenario mundial}

De 1940 hasta 1982, el escenario global del petróleo sufrió una serie de cambios significativos. En ese periodo de 42 años, las diversas regiones del mundo sufrieron muchos cambios en la producción de petróleo y en sus reservas probadas. La producción y las reservas mundiales hasta 1970 tuvieron un incremento gradual y constante que cambió en los años posteriores cuando la situación global de inestabilidad política, económico y social en diversos países devino en un constante periodo de cambios que se reflejaron en el tema petrolero: en su producción y las reservas probadas globales.

\section{Producción y reservas mexicanas: la estabilidad posterior a la expropiación}

La expropiación petrolera significó un aumento constante en diversos aspectos de la industria mexicana. De 1938 a 1946, las reservas pasaron de mil 276 millones de barriles a mil 437 millones (aumento de $13 \%$ ). De 1946 a 1953, el aumento alcanzó los 2 mil 241 millones de barriles (56\%). De 1952 a 1958, las reservas pasaron de 2 mil 241 millones a 4 mil 70 millones de barriles (aumento de $82 \%$ ); mientras que la producción diaria pasó de 216 mil barriles diarios (total de casi 79 millones) hasta 276 mil barriles diarios (total anual de más de 100 millo- 
nes de barriles, aumento de $28 \%$ ). Hasta 1964, las reservas probadas alcanzaron los 5 mil 227 millones de barriles; mientras la producción diaria llegó a 354 mil barriles (total anual de 129.5 millones). Sin embargo, hasta 1970, las reservas aumentaron únicamente el $7 \%$, hasta alcanzar 5 mil 568 millones; aunque la producción aumentó 38 \% hasta llegar a 487 mil barriles diarios (total anual de 177.5 millones).

Gráfica 2. Reservas totales de hidrocarburos, en Millones de Barriles, de 1938-1976

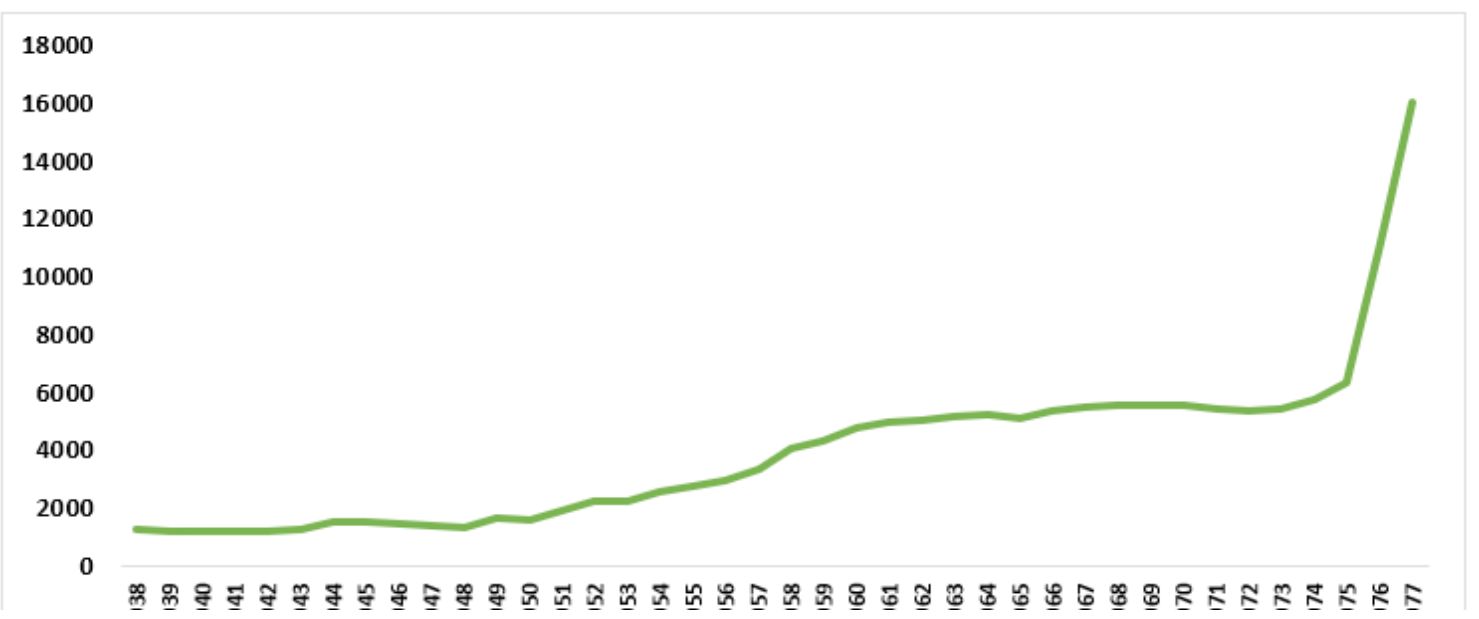

Fuente: elaboración propia, a partir de información del Anuario Estadístico de PEMEX, de 1977 y 1988.

De 1938 a 1946, la producción aumentó de 39 millones a 49 millones de barriles (28 \%). Conforme a la productividad diaria, México pasó de 106 mil barriles, en 1938, a 136 mil barriles, en 1946. De 1946 a 1952, la producción diaria pasó de 136 mil barriles diarios (49.5 millones totales) hasta alcanzar los 216 mil barriles diarios, (casi 79 millones). Las reservas aumentaron $76 \%$ en los de 1938 a 1952; mientras que la producción total y diaria aumentó $103 \%$.

Gráfica 3. Producción de crudo, condensado y líquido, en miles de barriles, de 1938-1976

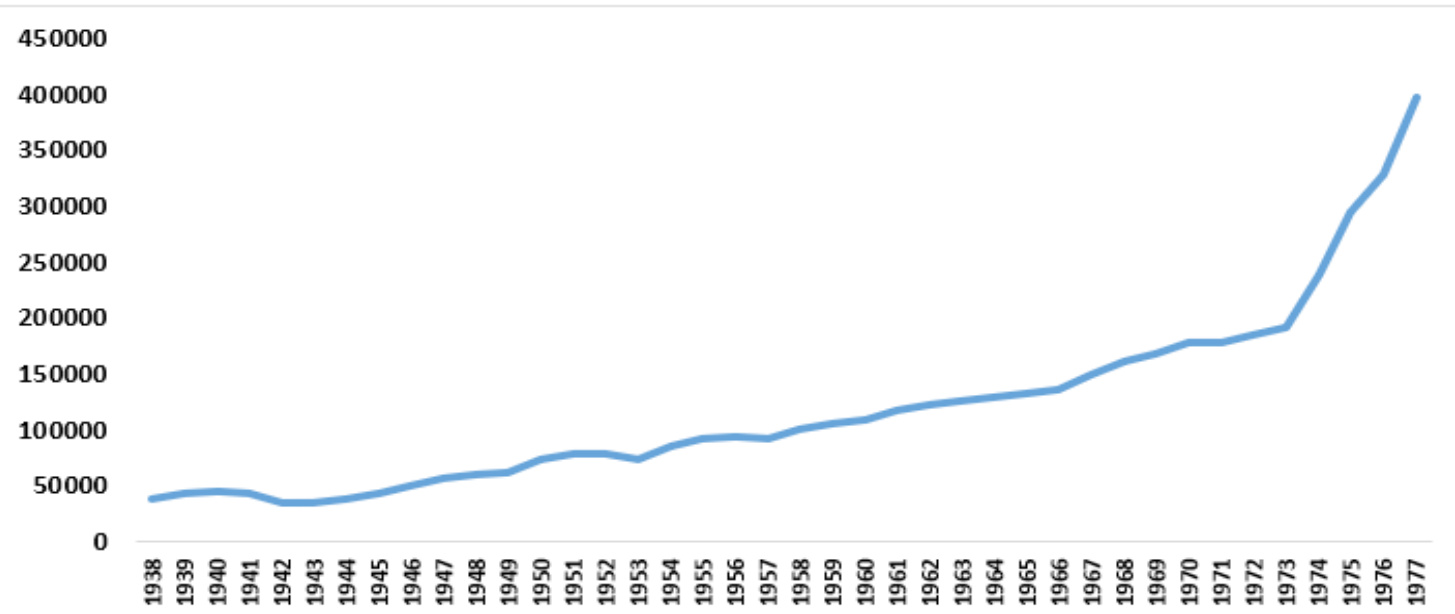

Fuente: Elaboración propia, a partir de información del Anuario Estadístico de PEMEX, de 
1977 y 1988.

Por la crisis petrolera de la década de 1970, México generó una sobreexplotación de sus hidrocarburos. Hasta 1976, las reservas probadas alcanzaron 11 mil 160 millones de barriles (aumento de $100 \%$ respecto a 1970); mientras que la producción diaria llegó a 894 mil barriles (más de 327 millones de total anual). Hasta 1982, las reservas probadas crecieron $545 \%$ hasta alcanzar los 72 mil 8 millones de barriles en 1982; mientras la producción diaria alcanzó los 2.7 millones de barriles diarias, un aumento del $207 \%$.

\section{Exportaciones mexicanas de crudo y derivados}

El medio internacional tuvo una repercusión en el mercado global del petróleo, por lo que las exportaciones mexicanas tuvieron un periodo de inestabilidad. Entre 1938 y 1945, las exportaciones mexicanas de hidrocarburos pasaron de casi 9 millones de barriles hasta poco menos de 5 millones en 1945. Hasta 1952, el país exportó más de 15 millones de barriles, pero hasta 1958, México únicamente exportó poco más de 11.5 millones de barriles. Hasta 1964, las exportaciones mexicanas llegaron a 17.1 millones.

Gráfica 4. Exportaciones totales, crudo y derivados, en miles de barriles, de 1938-1976

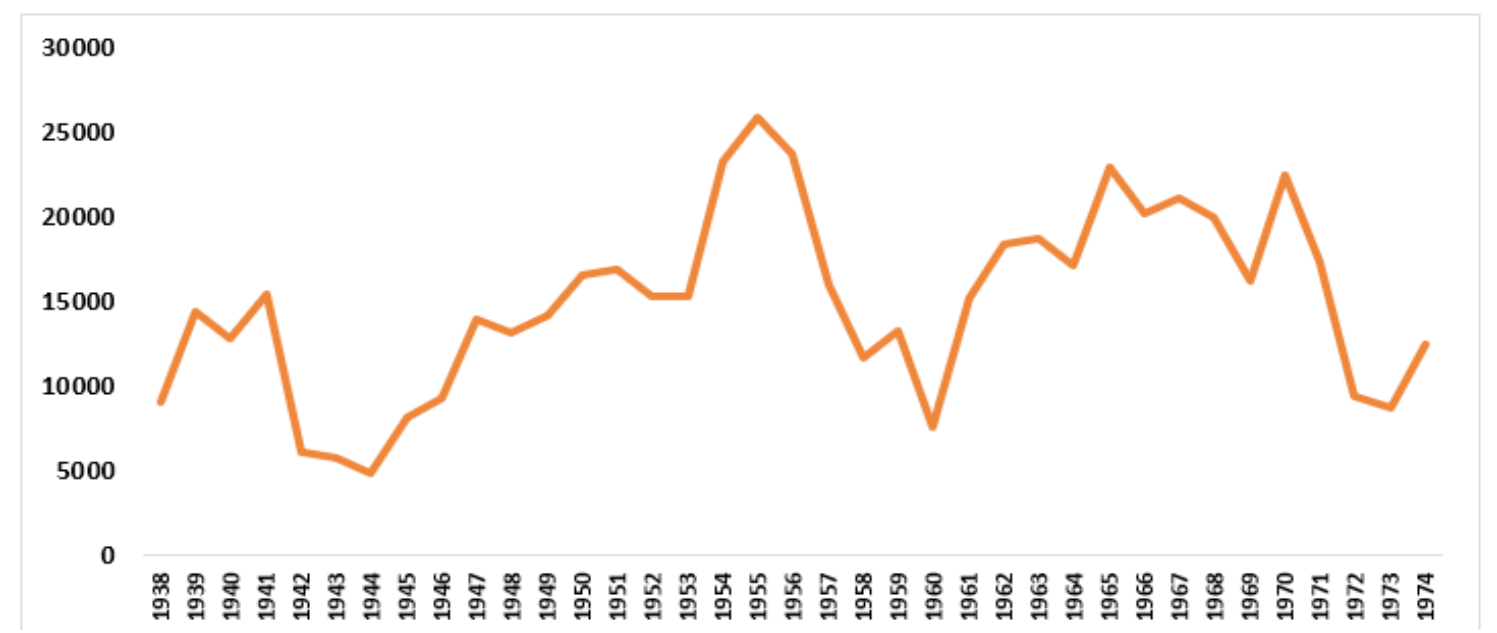

Fuente: elaboración propia, a partir de información del Anuario Estadístico de PEMEX, de 1988.

En los primeros años de la década de 1970, la inestabilidad global generó un descenso en las exportaciones de hidrocarburos mexicanos. De 1964 a 1970, las exportaciones alcanzaron 22.4 millones de barriles. A partir de la crisis de la OPEP, México pasó de exportar 8.6 millones de barriles, en 1973, a 12.4 millones en 1974, alcanzando un tope de casi 56 millones exportados en 1982, muestra de la sobre explotación petrolera de esa década. 
Gráfica 5. Exportaciones totales, crudo y derivados, en miles de barriles, de 1970-1988

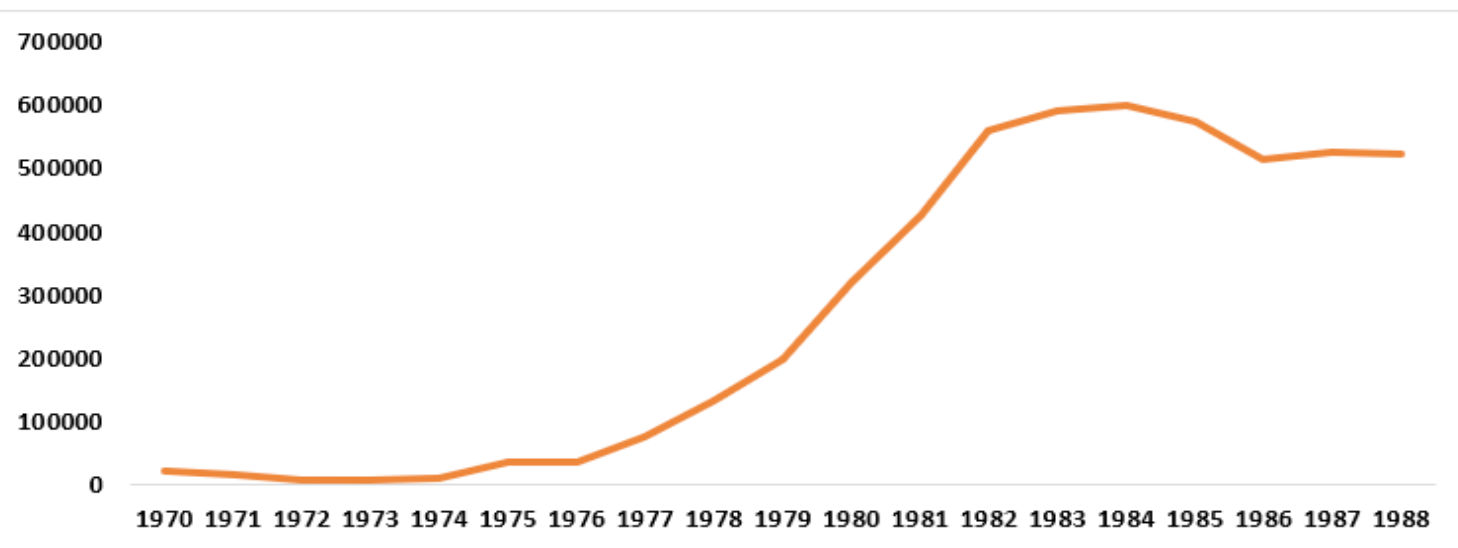

Fuente: Elaboración propia, a partir de información del Anuario Estadístico de PEMEX, de 1988.

El papel de México en el entorno global fue en aumento hasta 1982. La crisis de la década de 1970 significó un aumento en las reservas, exportaciones y producción de petróleo mexicano. Poco a poco, la presencia mexicana internacional aumentó dándole, al gobierno, medios para financiar sus políticas de bienestar social y metiendo al país en una extrema dependencia sobre el petróleo. De 1982 a 1988, las exportaciones pasaron de casi 56 millones a poco más de 52 millones de barriles.

Éste sexenio generó un último momento para la forma de producción mexicana de hidrocarburos y también fue el período clave de cambio para la adopción de las políticas económicas que dieron paso al Neoliberalismo.

En este escenario, de 1979 a 1982, las exportaciones netas pasaron de 532.8 mil barriles diarios hasta 1.4 millones (180\%), con ganancias que pasaron de 3 mil 811 millones de dólares a 15 mil 622 millones de dólares (310 \%). De 1982 a 1988, las exportaciones pasaron de 1.4 millones a 1.3 millones de barriles; mientras que las ganancias pasaron de 15.6 millones de dólares a 5.8 millones de dólares. 
Gráfica 6. Exportaciones netas de petróleo crudo. (Millones de dólares, miles de barriles diarios, de 1979 a 1982)

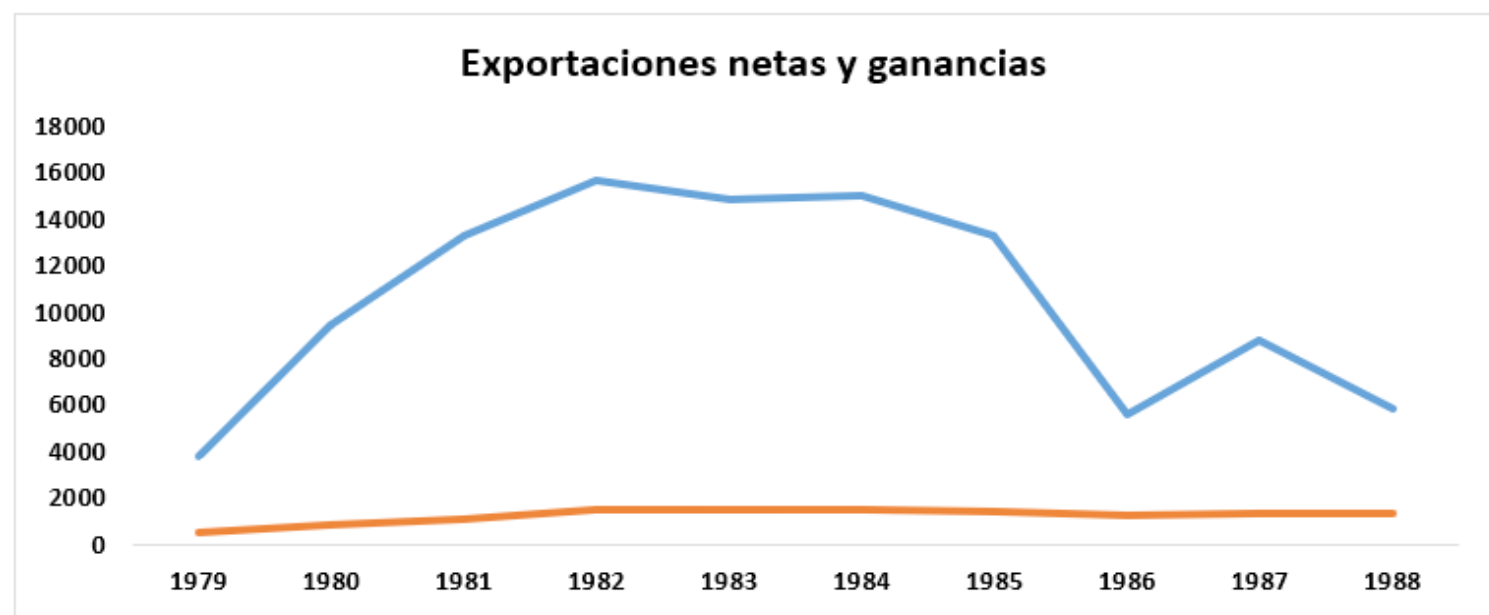

Fuente: Elaboración propia, a partir de información del Anuario Estadístico de PEMEX, de 1988.

Con Miguel De la Madrid, 1982 a 1988, las reservas totales de hidrocarburos -incluidos gas líquido y seco- descendieron de poco más de 72 mil millones de barriles a 67.6 mil millones de barriles. Mientras que el país pasó de producir 1.3 mil millones de barriles (2.7 millones diarios), en 1976, a generar mil 248 millones (2.5 millones por día) en 1988. Lo anterior significó un descenso en la producción y reservas intensificando la crisis que vivió el país ese sexenio (PEMEX, 1988). La balanza comercial de hidrocarburos también mostró un cambio ese sexenio: mientras las exportaciones fueron en descenso las importaciones aumentaron. Las exportaciones pasaron de un millón 492 mil a un millón 306 mil; y las ganancias descendieron de 15.6 mil millones a 5 mil 854 millones. En contraparte, las importaciones ascendieron de 9.1 mil barriles a 81.8 mil barriles diarios; es decir, un gasto que pasó de 149.3 millones de dólares a 379.6 millones de dólares.

Tabla 1. Balanza de comercio exterior de Hidrocarburos del sexenio de Miguel de la Madrid, 1982-1988

\begin{tabular}{|c|c|c|c|c|}
\hline \multirow{2}{*}{ Año } & \multicolumn{2}{|c|}{ Exportaciones } & \multicolumn{2}{c|}{ Importaciones } \\
\cline { 2 - 5 } & Millones de dólares & $\begin{array}{c}\text { Miles de barriles } \\
\text { diarios }\end{array}$ & Millones de dólares & $\begin{array}{c}\text { Miles de barriles } \\
\text { diarios }\end{array}$ \\
\hline 1982 & 15622.7 & 1492.1 & 149.3 & 9.1 \\
1983 & 14821.3 & 1537 & 263.3 & 18.1 \\
1984 & 14967.6 & 1524.6 & 355.4 & 33.9 \\
1985 & 13305 & 1439 & 486.2 & 54 \\
1986 & 5582 & 1289.6 & 360.3 & 7.1 \\
1987 & 8775.9 & 1345 & 413.7 & 81.8 \\
\hline
\end{tabular}

Fuente: Elaboración propia, con información del Anuario Estadístico de PEMEX, 1990. 
Al final del sexenio de De la Madrid, el país mantenía una situación de crisis extendida por lo que México debía implementar medidas políticas para revertirlas. Estas políticas neoliberales estaban dirigidas a mantener una apertura económica en todos los sectores del país y la industria petrolera tenía que abrir diversos sectores en su producción para poder intervenir en la globalización del mercado pero sin interferir en los aspectos identitarios del mismo.

\section{El Neoliberalismo y su repercusión en la industria petrolera de México}

Los acontecimientos de la década de 1970 replanteó el papel del Estado dentro de las tareas básicas del crecimiento de los países y dio fin a la intervención estatal dentro de los temas económicos marcando el inicio de un nuevo proceso coyuntural de la economía y la política: el Neoliberalismo (Cruz, 2002).

El nuevo escenario global, y los organismos financieros globales, obligaron a los Estados en crisis a reestructuren sus estrategias económicas y financieras. Los países debían cambiar sus estructuras para cumplir las exigencias del Fondo Monetario Internacional y el Banco Mundial y así aplicar las políticas neoliberales. En México, estas políticas recayeron en tres acciones específicas: la primera, una reforma fiscal que amplíe la base gravable, baje la tasa de impuestos y reduzca el impuesto al valor agregado (IVA) para incrementar los ingresos fiscales; en segundo lugar, reducir - o en algunos casos eliminar - el control de precios, las barreras aduanales, la protección de monopolios, las subvenciones y la rigidez en el mercado en las que había caído con la intervención del Estado; y por último, la privatización de las empresas paraestatales para reducir el peso y los gastos del Estado (Revueltas, 1996). Los gobiernos que buscaron frenar los problemas estructurales adoptaron las medidas que la nueva tendencia neoliberal indicaban cancelando programas de bienestar social financiados por el Estado, aflojaron las leyes laborales, desarmaron las estructuras formadas por los Estados y permitieron la compra de empresas paraestatales por privados y extranjeros (Cruz, 2002).

Para América Latina, y para México, el neoliberalismo dio fin al modelo de Industrialización por Sustitución de Importaciones para buscar un crecimiento hacia el exterior gracias a las exportaciones de productos estratégicos —idealmente, con explotación privada en esos recursos - . La apertura de sectores estratégicos ayudarían a incrementar y mejorar la productividad y la repartición de los ingresos modernizando el mercado interno (Revueltas, 1996). Sin embargo, las políticas neoliberales únicamente generaron una dependencia hacia el mercado estadounidense.

En 1988, el país tuvo un pequeño repunte en su desarrollo y el presidente Carlos Salinas buscó mayor estabilidad. La firma del TLCAN significó crecimiento y estabilidad en los índices de desarrollo al pasar de $1.24 \%$ en 1988 a $5.06 \%$ en 1990. Al momento de la entrada en vigor del Tratado de Libre Comercio en 1994, el país contaba con un crecimiento de $4.72 \%$ pero descendió hasta $-5.75 \%$ con la crisis de 1995. Para 1996, la tasa de crecimiento alcanzó 5.87 \% y de $6.96 \%$ en 1997. Para 1999, hubo una caída hasta llegar a $2.66 \%$, aunque la alternancia motivó el crecimiento para llegar a 5.29 \% en el 2000 (Banco Mundial, 2017).

Revista Política, Globalidad y Ciudadanía, Vol. 5 No. 10, Julio - Diciembre 2019, Universidad Autónoma de Nuevo León, Monterrey, México, ISSN 2395-8448. 110-133. http://revpoliticas.uanl.mx/index.php/RPGyC/article/view/124 
Con Salinas, las reservas totales de hidrocarburos pasaron de 67.6 millones de barriles en 1989 a 64.5 millones de barriles en 1994. La caída continuó en el sexenio de Zedillo cuando las reservas totales pasaron de 63.2 millones en 1995 a 58.2 millones de barriles en el 2000 (PEMEX, 1990; y PEMEX, 1999). Con esto, los primeros dos sexenios neoliberales tuvieron una tendencia de decrecimiento constante.

Gráfica 7. Reservas totales en el sexenio de Carlos Salinas y Ernesto Zedillo, 1988-2000

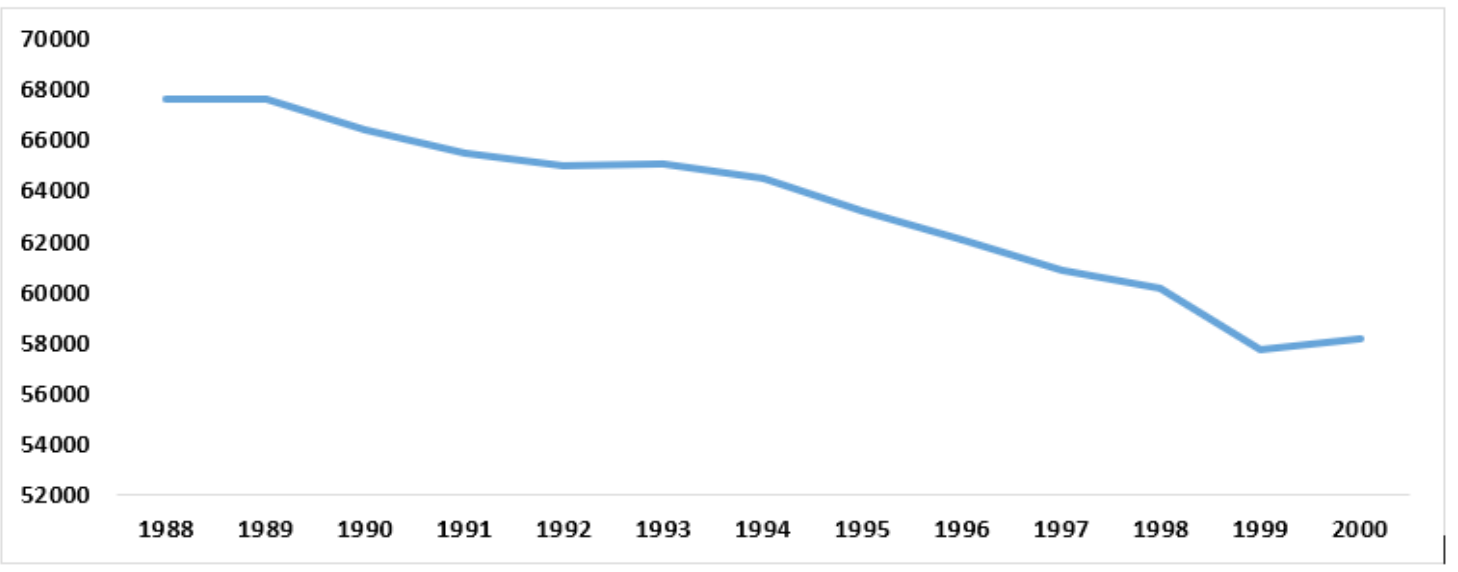

Fuente: Elaboración propia, con información del Anuario Estadístico de PEMEX, 19901999.

De 1988 a 1994, la producción diaria de hidrocarburos aumentó de 2.5 millones de barriles a 2.6 millones de barriles diarios. Mientras que de 1995 al 2000, continuó el aumento de 2.6 millones de barriles a superar 3 millones gracias al hallazgo de nuevos pozos en Campeche (PEMEX, 1990; y PEMEX, 1999). De esta manera, en los sexenios de Salinas y Zedillo, mientras las reservas descendieron, la producción diaria aumentó.

Gráfica 8. Producción diaria en el sexenio de Carlos Salinas y Ernesto Zedillo, 1988-2000

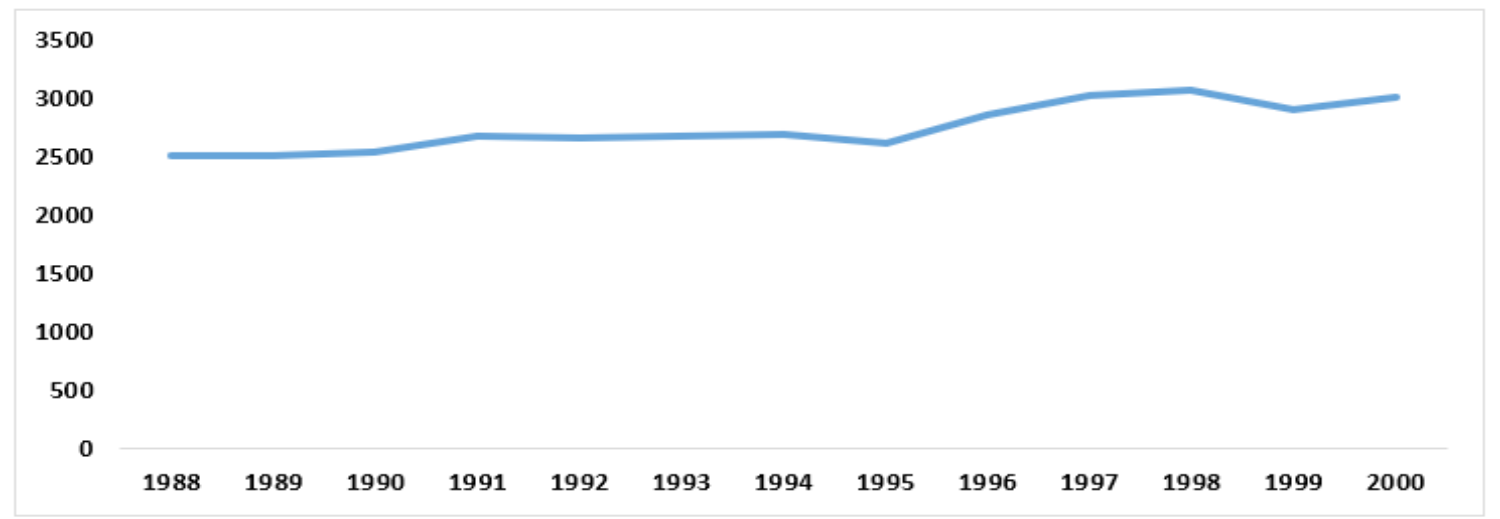

Fuente: Elaboración propia, con información del Anuario Estadístico de PEMEX, 1990- 
1999. Nota: Producción (Miles de barriles diarios).

De 1988 a 1994, la balanza comercial petrolera mostró un mínimo crecimiento a las exportaciones pero las importaciones de productos petrolíferos incrementaron. Las exportaciones pasaron de un millón 277 mil barriles diarios ( 7 mil 281 millones de dólares) a un millón 307 mil barriles (6 mil 624 millones de dólares). Sin embargo, las importaciones aumentaron de 122 mil barriles (800.4 millones de dólares) en 1989 a 188.7 mil barriles diarios (mil 466 millones de dólares) en 1994. De 1994 al 2000, la situación fue similares: las exportaciones pasaron de poco más de un millón 300 mil barriles diarios ( 6 mil 624 millones de dólares) a un millón 652 mil (14 mil 886 millones de dólares). Igualmente aumentaron las importaciones, que pasaron de 188 mil barriles diarios (mil 466 millones de dólares) a 365 mil barriles por día (4 mil 699 millones de dólares), acortando la distancia entre las ganancias por exportaciones y pérdidas por importaciones.

Tabla 2. Balanza de comercio exterior de Hidrocarburos del sexenio de Carlos Salinas y Ernesto Zedillo, 1988-2000

\begin{tabular}{|c|c|c|c|c|}
\hline \multirow{2}{*}{ Año } & \multicolumn{2}{|c|}{ Exportaciones } & \multicolumn{2}{c|}{ Importaciones } \\
\cline { 2 - 5 } & Millones de dólares & $\begin{array}{c}\text { Miles de barriles } \\
\text { diarios }\end{array}$ & Millones de dólares & $\begin{array}{c}\text { Miles de barriles } \\
\text { diarios }\end{array}$ \\
\hline 1989 & 7281 & 1277.8 & 800.4 & 122 \\
1990 & 8899.9 & 1277.1 & 970 & 108.5 \\
1991 & 7286.2 & 1368.7 & 1253.6 & 142.5 \\
1992 & 7448.1 & 1367.8 & 1560.1 & 172 \\
1993 & 6441 & 1337.1 & 1445.6 & 176.6 \\
1994 & 6624.1 & 1307.4 & 1466 & 188.7 \\
1995 & 7479.6 & 1305.5 & 1206 & 139.5 \\
1996 & 10704 & 1543.8 & 1642 & 177.3 \\
1997 & 10340.1 & 1720.7 & 2666 & 298.6 \\
1998 & 6465.6 & 1741.2 & 2231.9 & 334.3 \\
1999 & 8858.8 & 1553.5 & 2669.7 & 325.3 \\
2000 & 14886.9 & 1652.1 & 4699.4 & 365 \\
\hline
\end{tabular}

Fuente: Elaboración propia, con información de los Anuarios Estadísticos de PEMEX, 19901999-2001.

Es de notar que las exportaciones del país estaban conformadas por crudo de diferentes zonas de país, gas natural y productos petrolíferos — gasolinas y combustibles - y petroquímicos - azufres, propilenos, entre otros- Si bien, hubo alzas en las exportaciones de crudo y derivados, también fue mayor la importación de éstos mostrando el poco interés de PEMEX por mantener su papel como principal productor en el país en estos aspectos.

\section{El siglo XXI y el camino a la reforma energética}


Para el año 2000, la impopularidad presidencial y la expectativa que despertó el Partido Acción Nacional (PAN), y su candidato Vicente Fox Quezada, resultaron en la primera alternancia en la presidencia. Como presidente, Fox cambió la visión del petróleo como columna vertebral del desarrollo nacional y permitió reuniones de altos funcionarios del gobierno y del sector energético con empresarios estadounidenses y canadienses para invertir recursos privados en materia energética (Cuellar, 2008) firmando convenios de cooperación científica y tecnológica (con Royal Dutch Shell; Petrobras y Statoil; y en 2006 con Nexen y Chevron-Texaco), aunque no implicaría operaciones comerciales y a pesar del discurso proteccionista (Lomas, s/f). Para el sexenio de Calderón, ese mismo ímpetu ocasionó la búsqueda de una reforma energética que sería lograda en el 2008 y que traería cambios, de nuevo, en la estructura energética y petrolera del país.

El gobierno de Fox permitió la entrada, masiva y libre de aranceles, de destilados de hidrocarburos provenientes de Estados Unidos y Canadá, al tiempo que aceleró la extracción de crudo. En 2005, el congreso reformó la Ley para permitir la generación de energía junto con Estados Unidos (Cárdenas, 2009). El descenso en las reservas probadas, y la sospecha que solamente llegarían hasta el 2012, aportó el argumento para permitir la incursión privada en el ámbito petrolero y así evitar futuras importaciones (Salinas, 2008). Del 2001 al 2006, las reservas totales pasaron de 56 mil 154 millones a 46 mil 417 millones de barriles. De 2006 a 2012, las reservas totales disminuyeron al pasar de 46 mil 417 millones de barriles a 43 mil 837 millones.

Gráfica 9. Reservas totales en el sexenio de Vicente Fox y Felipe Calderón, 2000-2012

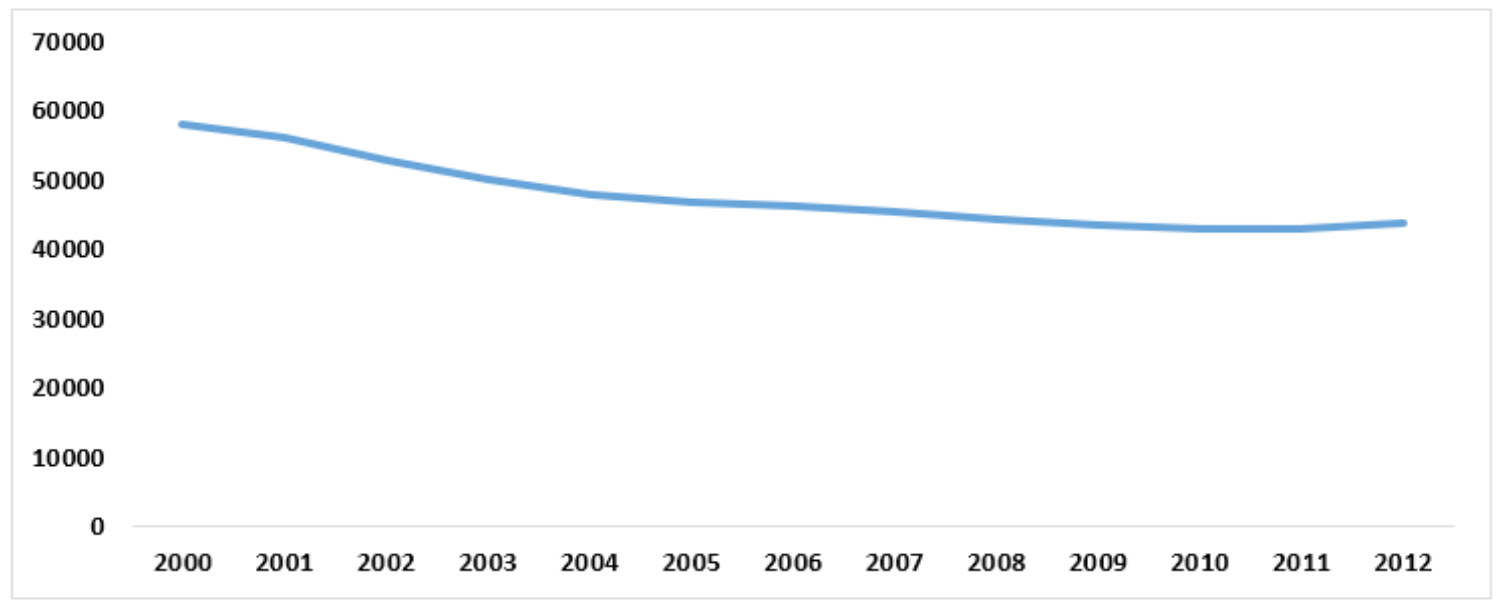

Fuente: Elaboración propia, con información de los Anuarios Estadísticos de PEMEX, del 2001 al 2013.

De 2000 al 2006, la producción de crudo y derivados incrementó — tímidamente — al pasar de 3 millones 127 mil barriles a 3 millones 255 mil barriles diarios. De 2006 a 2012, la producción pasó de 3 millones 255 mil barriles a 3 millones 548 mil barriles diarios. En resumen, en los sexenios panistas, mientras las reservas descendían la producción diaria aumentaba, lo que apoyó el argumento sobre la disminución de las reservas, la mayor exigencia del mercado y la 
gran dependencia de las finanzas del país sobre el petróleo

Gráfica 10. Producción diaria en el sexenio de Vicente Fox y Felipe Calderón, 2000-2012

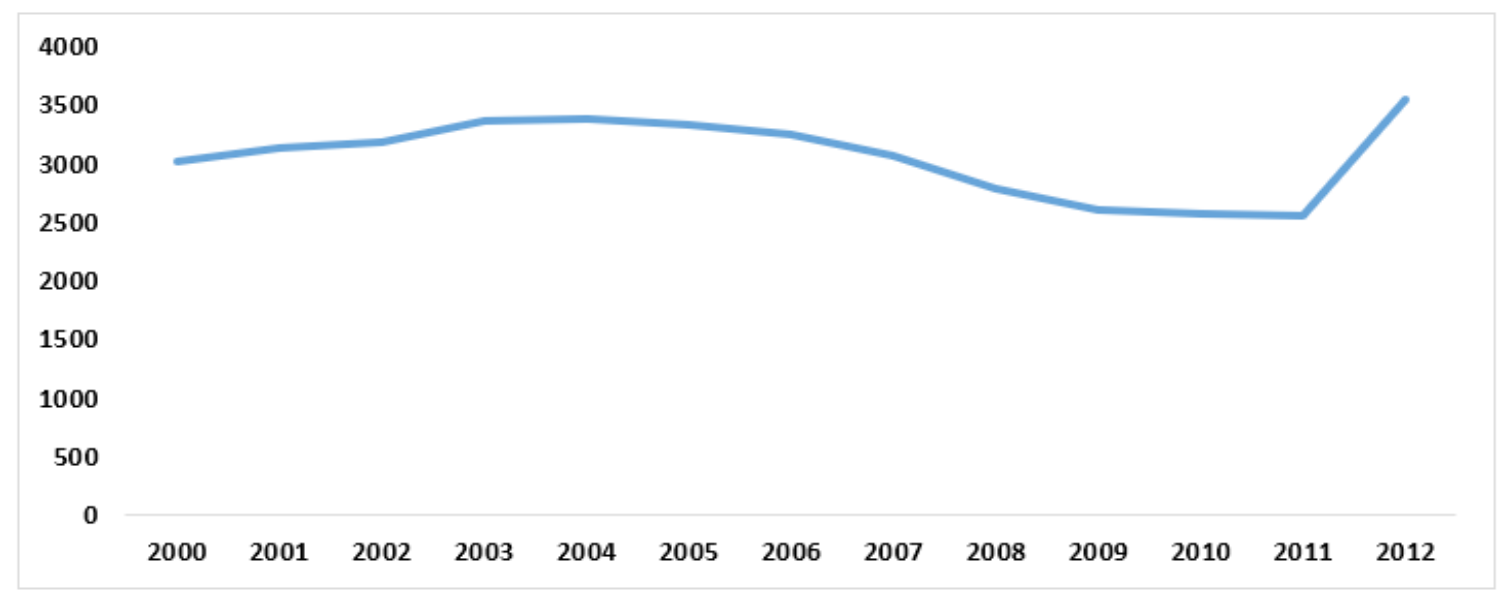

Fuente: Elaboración propia, con información de los Anuarios Estadísticos de PEMEX, de 2001 a 2013. Nota: Producción (Miles de barriles diarios)

Durante el sexenio de Fox, el país tuvo los ingresos petroleros más altos de su historia (orbitaron arriba de 78 dólares por barril) (Cuellar, 2008). Entre el 2000 y el 2006, las exportaciones pasaron de un millón 652 mil barriles diarios (14 mil 886 millones de dólares) a un millón 792 mil barriles por día (34 mil 706 millones de dólares); mientras que las importaciones pasaron de 365 mil barriles diarios (4 mil 700 millones de dólares) a 368 mil barriles diarios (11 mil 291 millones de dólares), un aumento de más de $150 \%$. La diferencia entre ganancias por exportación y gastos para importación de petrolíferos era cada vez más corta: en 2006 el gasto era de casi el $33 \%$ del total de los ingresos.

De 2006 a 2012, las exportaciones disminuyeron al pasar de un millón 792 mil barriles diarios (más 34 mil millones de dólares) a un millón 255 mil barriles por día (casi 47 mil millones de dólares). Conforme a las importaciones, pasaron de casi 369 mil barriles diarios (más de 11 mil millones de dólares) a casi 671 mil barriles (más de 31 mil millones de dólares). Los gastos que el país requería para importar combustibles correspondía a dos tercios - $66.40 \%$ - de las ganancias por exportar petróleo crudo. 
Tabla 3. Balanza comercial de hidrocarburos del sexenio de Vicente Fox y Felipe Calderón, 2000-2012

\begin{tabular}{|c|c|c|c|c|}
\hline \multirow[b]{2}{*}{ Año } & \multicolumn{2}{|c|}{ Exportaciones } & \multicolumn{2}{|c|}{ Importaciones } \\
\hline & Millones de dólares & $\begin{array}{c}\text { Miles de barriles } \\
\text { diarios }\end{array}$ & Millones de dólares & $\begin{array}{c}\text { Miles de barriles } \\
\text { diarios }\end{array}$ \\
\hline 2000 & 14886.9 & 1652.1 & 4699.4 & 365 \\
\hline 2001 & 11590.6 & 1709.9 & 4108.5 & 335.3 \\
\hline 2002 & 13528.8 & 1715.4 & 3316.5 & 243.6 \\
\hline 2003 & 16676.3 & 1843.9 & 3993.8 & 199.9 \\
\hline 2004 & 21257.9 & 1870.3 & 5565.2 & 234.2 \\
\hline 2005 & 28329.4 & 1817.1 & 9363.5 & 333.7 \\
\hline 2006 & 34706.8 & 1792.7 & 11291.6 & 368.9 \\
\hline 2007 & 37937.5 & 1686.2 & 16938.2 & 494.6 \\
\hline 2008 & 43341.5 & 1403.4 & 23474.1 & 552.5 \\
\hline 2009 & 25605.4 & 1222.1 & 14108.7 & 519.2 \\
\hline 2010 & 35985.4 & 1360.5 & 21448.8 & 627.3 \\
\hline 2011 & 49379.6 & 1337.8 & 30804.6 & 678.2 \\
\hline 2012 & 46852.4 & 1255.5 & 31098.9 & 670.8 \\
\hline
\end{tabular}

Fuente: Elaboración propia, con información de los Anuarios Estadísticos de PEMEX, del 2001 al 2013.

De esta manera, si bien el gobierno de Vicente Fox en el tema petrolero y mantuvo un crecimiento constante - comparado sexenios anteriores-, también aumentaron las exportaciones y las importaciones de productos refinados. La política petrolera de Calderón estuvo encaminada a la privatización de las actividades de producción. La inversión pública para PEMEX disminuyó considerablemente (de 2.9 \% del PIB en 1982 a $0.57 \%$ en 2007) consiguiendo que las principales actividades petroleras dejaran de desarrollarlas trabajadores y técnicos de la paraestatal y fueran cedidos, por contratos de servicio múltiples, a empresas privadas (Cárdenas, 2009). Ésto generó Calderón y Peña Nieto buscaran reforzar la industria petrolera y explorar nuevas regiones para aumentar las reservas.

La reforma y la firma de contratos con empresas privadas buscaron generar miles de empleos, dinamizar la industria petrolera — clave para México - y reducir la dependencia sobre las importaciones de combustibles y gasolinas; reforzando la posición del petróleo como elemento clave para el desarrollo de México (Rivas, 2009).

La reforma también modificó la Ley Federal de Presupuestos y Responsabilidad Hacendaria (último trimestre de 2008 y previo a la Ley de Ingresos del 2009) convirtiendo en deuda pública las PIDIREGAS de PEMEX (178 mil millones de pesos o 14 mil millones de dólares). Con este cambio, el gobierno privatizó casi la totalidad de la inversión de PEMEX, que pasó del 39 \% en 1998 al $88 \%$ en el 2008 (Gutiérrez, 2011).

Repercusiones de la reforma energética del 2013 y los gobiernos de Peña Nieto y López Obrador

La reforma energética del 2013 buscaba fortalecer al país, los procesos de producción petrolera y la tecnología para explorar y explotar fuentes alternas que otros países habían tomado 
para continuar con el desarrollo del país. Entre 1980 y 1990, la dependencia gubernamental sobre el petróleo disminuyó aunque no para las finanzas públicas. Las aspiraciones por aumentar el crecimiento del país - a través de la inversión privada al sector petrolero- fracasaron, entre otras cosas, por la caída de los precios internacionales del petróleo (Freindenberg y Aparicio, 2016).

Para julio de 2008, el precio internacional del petróleo aumentó hasta un máximo de $\$ 120.5$ dólares por barril. Sin embargo, hasta diciembre de 2008, los precios internacionales alcanzaron un mínimo de $\$ 33.70$ dólares. Entre 2009 y febrero de 2011, hubo cierto ascenso y estabilidad entre los $\$ 112.82$ y $\$ 90$ dólares por barril que duró entre 2014 hasta 2017 cuando alcanzó un máximo de $\$ 45.70$ dólares. A partir de marzo de 2016, el precio de la mezcla mexicana mantuvo un crecimiento constante hasta octubre del 2018 cuando alcanzó $\$ 71.29$ dólares por barril y a partir de ese año ha ido en descenso hasta $\$ 58.41$ de septiembre de 2019.

Gráfica 11. Precio internacional del petróleo (Periodo mensual. De enero de 2005 a agosto de 2019)

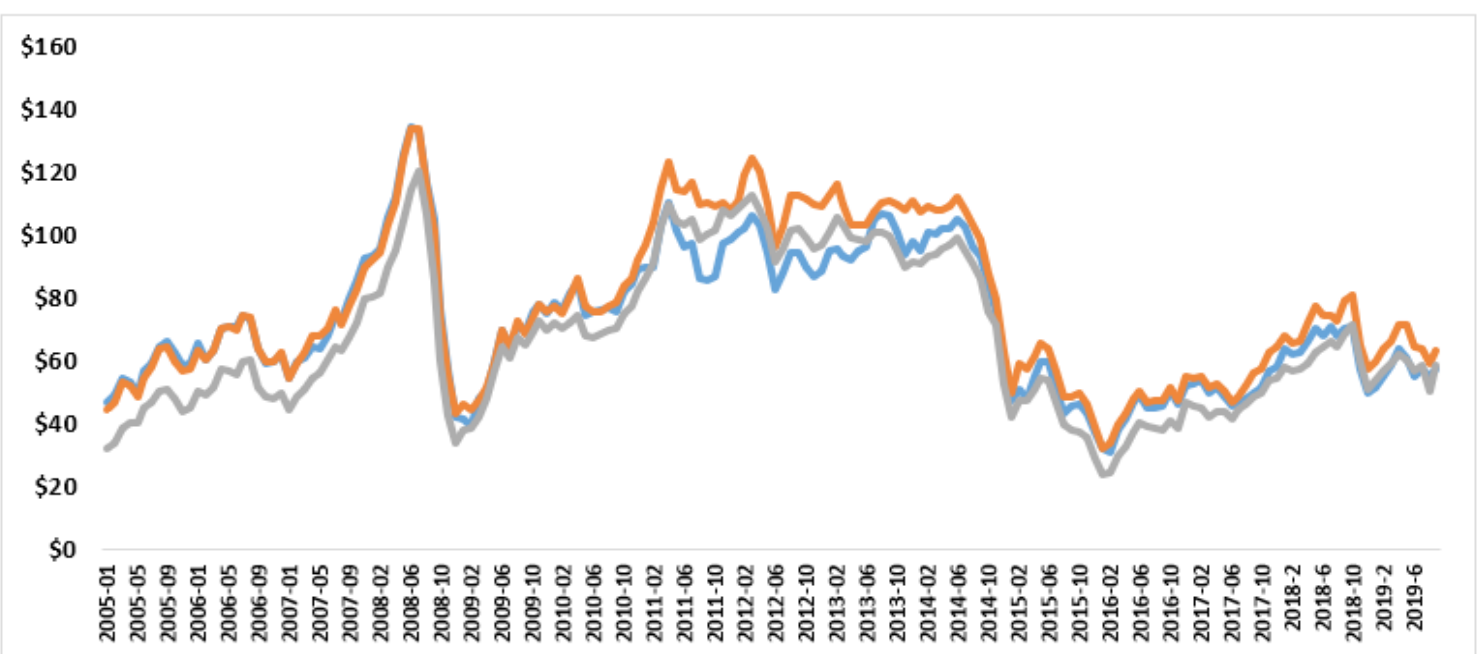

Fuente: Elaboración propia, con información del Servicio Geológico Mexicano de la Secretaria de Energía, BANXICO, y DatosMacro.com.

Con Enrique Peña Nieto, las exportaciones petroleras disminuyeron. De 2012 a 2017, las exportaciones pasaba un millón 255 mil barriles por día (casi 47 mil millones de dólares) a un millón 184 mil barriles diarios (apenas superiores a 26 mil millones de dólares). Mientras que las importaciones aumentaron de 670 mil barriles ( 32 mil millones de dólares) a casi 980 mil barriles (32 mil 688 millones de dólares), significando que el país ha importado el $82.77 \%$ de lo exportado, equivalente a 6 mil 176 millones de dólares 
Tabla 5. Balanza de comercio exterior de hidrocarburos del sexenio de Enrique Peña Nieto y Andrés Manuel López Obrador, 2012-2019

\begin{tabular}{|c|c|c|c|c|}
\hline \multirow{2}{*}{ Año } & \multicolumn{2}{|c|}{ Exportaciones } & \multicolumn{2}{c|}{ Importaciones } \\
\cline { 2 - 5 } & Millones de dólares & $\begin{array}{c}\text { Miles de barriles } \\
\text { diarios }\end{array}$ & Millones de dólares & $\begin{array}{c}\text { Miles de barriles } \\
\text { diarios }\end{array}$ \\
\hline 2012 & 46852.4 & 1255 & 31099 & 671 \\
2013 & 42712 & 1189 & 28330.4 & 603 \\
2014 & 35638 & 1142 & 28454 & 640.6 \\
2015 & 18451 & 1172 & 20854 & 740 \\
2016 & 15582 & 1194 & 19868 & 799.5 \\
2017 & 20047 & 1174 & 26420 & 935 \\
2018 & 26512 & 1184 & 32688 & 980 \\
$2019+$ & 15730 & 1132 & 17110 & 855 \\
\hline
\end{tabular}

Fuente: Elaboración propia, con información de los Anuarios Estadísticos de 2007 a 2018 y los indicadores petroleros de PEMEX de 2019

Hasta septiembre de 2019, en el sexenio de Andrés Manuel López Obrador, las exportaciones han superado el millón 132 mil barriles al día (15 mil 730 millones de dólares), mientras que las importaciones apenas llegan a los 855 mil barriles (17 mil 110 millones de dólares) significando el $75.53 \%$ y mil 380 millones de dólares de diferencia.

De 2012 a 2018, las reservas totales del país disminuyeron de 43 mil 837 millones de barriles a 21 mil 89 millones. Por su parte, la producción nacional también descendió de superar los 3.5 millones de barriles diarios a un millón 833 mil barriles. Hasta septiembre de 2019, el promedio de producción llegó al millón 672 mil barriles por día y las reservas apenas sobrepasaron los 20 mil 453 millones de barriles.

Tabla 6. Reservas totales y producción en el sexenio de Enrique Peña Nieto y Andrés Manuel López Obrador, 2012-2019

\begin{tabular}{|c|c|c|}
\hline Año & $\begin{array}{c}\text { Reservas totales de hidrocarburos } \\
\text { (Millones de barriles) }\end{array}$ & $\begin{array}{c}\text { Producción de crudo, condensado y líquido. } \\
\text { (miles de barriles diarios) }\end{array}$ \\
\hline 2012 & 43837 & 3548 \\
2013 & 44530 & 2522 \\
2014 & 42158 & 2429 \\
2015 & 37405 & 2267 \\
2016 & 22223 & 2154 \\
2017 & 22149 & 1948 \\
2018 & 21089 & 1833 \\
$2019:$ & 20453 & 1672 \\
\hline
\end{tabular}

Fuente: Elaboración propia, con información de los Anuarios Estadísticos de 2007 a 2018 y los indicadores petroleros de PEMEX de 2019. 
De la mano del petróleo es un símbolo nacional, PEMEX ha sido la vaca sagrada a lo largo de las décadas. Sin embargo, la corrupción - falta de transparencia, independencia y rendición de cuentas - ha sido un tema importante en la paraestatal. Por esta razón, el gobierno de López Obrador trata de mantener una política de protección nacional siguiendo una estrategia diferente a la establecida por la reforma energética del 2013.

En ese sentido, desde 1988 hasta el 2004, las exportaciones pasaron de poco más de un millón 306 mil barriles diarios a poco más de un millón 870 mil barriles al día. De 2004 hasta septiembre de 2009, las exportaciones han disminuido hasta poco más de un millón 135 mil barriles diarios. Del total de exportaciones, el continente americano es el principal destino para el petróleo mexicano al pasar de 745 mil barriles diarios en 1988 hasta un millón 655 mil barriles diarios en 2004 (Estados Unidos, el principal receptor, pasó de casi a 685 mil barriles por día en 1988 hasta un millón 622 mil barriles hasta septiembre de 2019 792) (PEMEX, 1999-2019).

El segundo destino del petróleo mexicano ha sido Europa. Desde 1988, las exportaciones pasaron de 376 mil barriles por día hasta 195 mil barriles diarios, en 2019 (el principal destino fue España con 204 mil barriles al día en 1988 hasta 162 mil barriles diarios en 2014) (PEMEX, 1999-2014). En Asia y Medio Oriente, las exportaciones pasaron de 184 mil barriles diarios en 1988 hasta 316 mil barriles hasta septiembre de 2019 (Japón fue el principal destino con 174 mil barriles en 1988 hasta 2003 con 10 mil barriles al día, aunque a partir del 2000 India importa petróleo mexicano pasando de casi 5 mil a más de 80 mil barriles diarios) (PEMEX, 1999-2014). El último destino del petróleo mexicano es África aunque únicamente fue de 1997, cuando exportaba 12.7 mil barriles al día, hasta mil 400 barriles diarios en 2005.

Gráfica 12. Volumen de exportaciones de petróleo crudo de México por destino, 1988-2019

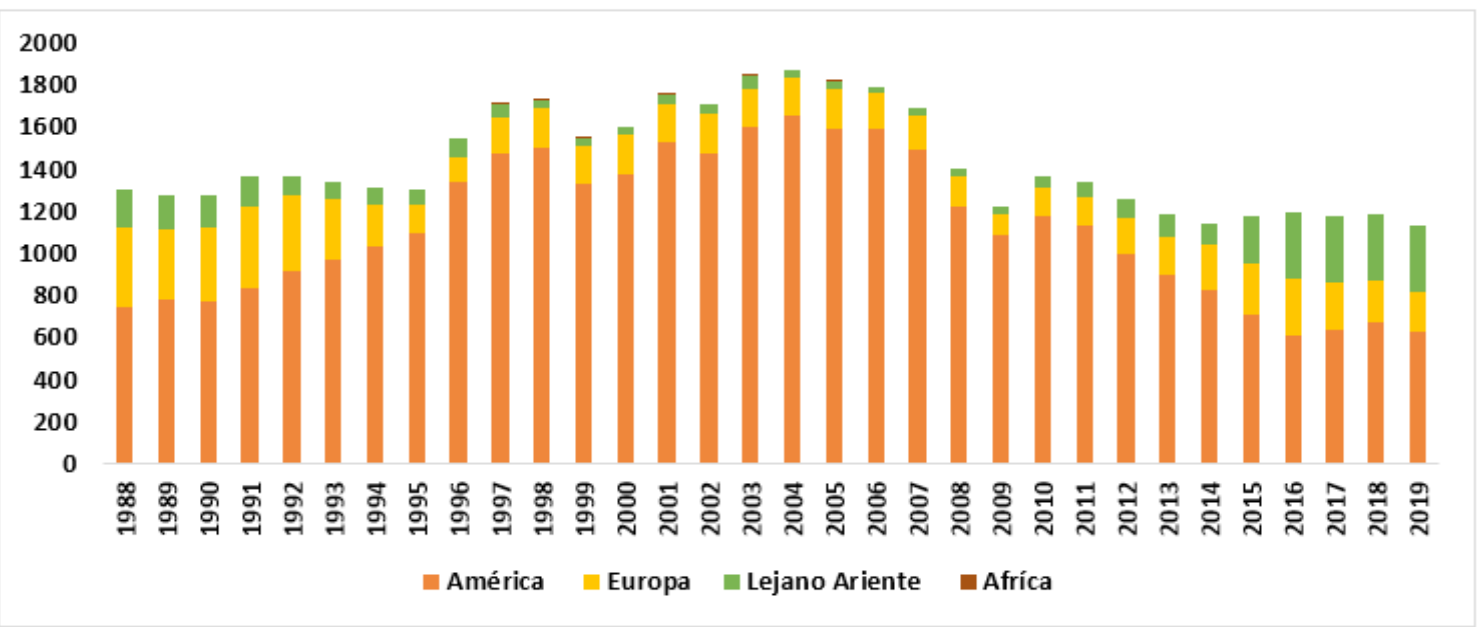

Fuente: Elaboración propia, con información de los Anuarios Estadísticos de 1988 a 2018 y la base de datos institucional de PEMEX.

Las ganancias por exportación de 1988 a 2018, pasó de 5 mil 854 millones hasta 43 mil 341 millones hasta alcanzar 26 mil 512 millones. Hasta septiembre de 2019, las exportaciones

Revista Política, Globalidad y Ciudadanía, Vol. 5 No. 10, Julio - Diciembre 2019, Universidad Autónoma de Nuevo León, Monterrey, México, ISSN 2395-8448. 110-133. http://revpoliticas.uanl.mx/index.php/RPGyC/article/view/124 
llegaron a 15 mil 730 millones de dólares. Del total de ganancias, América aportó de 3 mil 353 millones en 1988 hasta 15 mil 364 millones en 2018, y 8 mil 869 millones de dólares hasta septiembre de 2019. Europa pasó de mil 622 millones de dólares en 1988 a 4 mil 330 millones en 2018 y 2 mil 595 millones de dólares hasta septiembre de 2019. El Lejano Oriente pasó de 878 millones de dólares en 1988 a 6 mil 819 millones de dólares en 2018. Mientras que África aportó de 75 millones en 1997 a 7 millones de dólares 2005.

Gráfica 13. Valor de las exportaciones de petróleo crudo por destino geográfico, 1988-2019

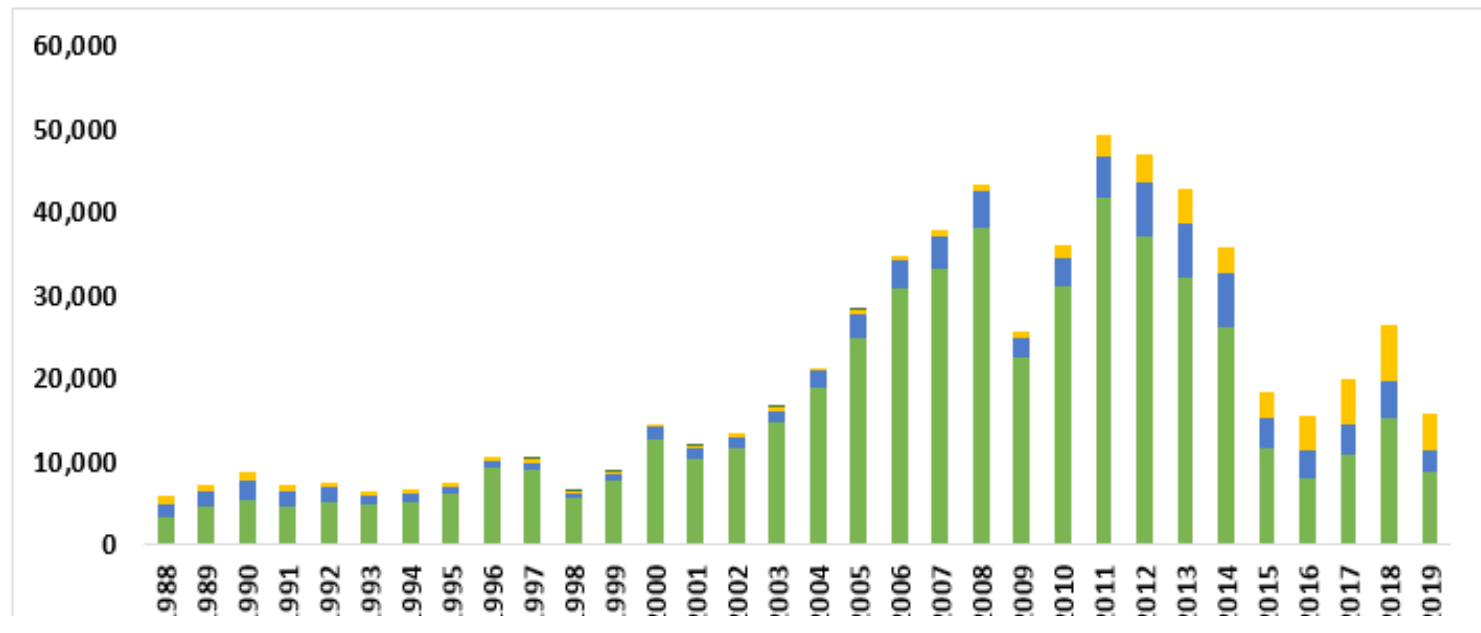

Fuente: Elaboración propia, con información de los Anuarios Estadísticos de 1988 a 2018 y la base de datos institucional de PEMEX.

En ese sentido, la exportación y las ganancias de crudo mexicano reflejan un declive. Por esa razón, el gobierno de López Obrador propone un cambio de rumbo de la producción que PEMEX y en la forma en la que el gobierno haga valer su propiedad sobre sus recursos naturales que ha mantenido, no solo desde la apertura económica, sino desde de la reforma energética del 2013.

La nueva visión gubernamental mantiene, e intensifica, el discurso político nacionalista alrededor del impulso a la seguridad y soberanía petrolera. En ese sentido, el gobierno del presidente López Obrador trazó en su Plan Nacional de Desarrollo "un propósito de importancia estratégica [...] es el rescate de Pemex y la CFE para que vuelvan a operar como palancas del desarrollo nacional" (Presidencia de la República, 2019, pág. 50). Como acciones para el cumplimiento de ese objetivo, el gobierno federal propone la rehabilitación de las refinerías ya existentes, la creación de la una nueva refinería en Dos Bocas (The Economist, 2019).

De igual manera, el presidente ha insistido en fortalecer a PEMEX con recursos extraordinarios obtenidos a través de la política de austeridad y recortes presupuestales a diversos sectores públicos. Sin embargo, analistas económicos argumentan que esa estrategia no tendrá los resultados esperados pues cambia los ejes de las reformas del 2008 y 2013: la explotación petrolera en aguas profundas — 500 metros de profundidad o menos — y ultra profundas — más de 1,500 
metros de profundidad-. Con esto, López Obrador demuestra no tener interés por continuar con los proyectos que iniciaron los gobiernos priistas y panistas en el periodo neoliberal, por lo que el presidente canceló la licitación de siete empresas privadas y entregó nuevas asignaciones a PEMEX (Solís, 2019).

A pesar de esto, PEMEX declaró que una de las estrategias del gobierno de López Obrador es asegurar la visión, a largo plazo, de las oportunidades exploratorias. En ese sentido, la comisionada Nacional de Hidrocarburos, Alma América Porres Luna, declaró que esperar a que los costos de las exploraciones en aguas profundas disminuyan tiene beneficios pero también perjuicios: "cuando una empresa quiera sacar el crudo en aguas profundas, el precio que tenga el hidrocarburo puede ser tan bajo que no sea económicamente viable, o el hidrocarburo tal vez ya no sea la energía que se requiera" (Solís, 2019). De esta manera, el presidente propone que la paraestatal tendrá una recuperación en tres años y el país volverá a ser autosuficiente en la producción de combustible. Sin embargo, las consultoras - como Standard and Poors y Mood$\mathrm{y}^{\prime} \mathrm{s}$ - ven con escepticismo la propuesta presidencial (BBC, 2019).

\section{3.- MÉTODO}

\section{Diseño}

El trabajo utiliza medios explicativos y analíticos al retomar todos los datos que proporciona PEMEX y otros medios que contabilizan las importaciones y exportaciones petroleras, así como países destino de ese crudo, precios internacionales y el tamaño de producción y reservas. De igual manera, los relaciona con los periodos presidenciales desde la aparición del petróleo en México y como estos periodos, a partir del neoliberalismo, crecieron, o no, con ayuda del petróleo.

Por esta razón, los recursos utilizados son los registros disponibles en los anuarios estadísticos de PEMEX, las bases de datos institucionales y otros registros disponibles para medir el incremento de las variables del estudio. En ese sentido, el estudio relacionó la importación y exportación con las reservas probadas y la producción nacional en el periodo de sustitución de importaciones y neoliberal para comprobar la repercusión de ésta política en la industria petrolera nacional.

Instrumentos

La investigación utilizó las bases de datos registradas en los anuarios estadísticos y las bases de datos institucionales de PEMEX, registros del Mundo Mundial, del Banco de México, de Méxicomaxico.com y los registros de Expansión para el precio internacional de petróleo Brent y WTI - L Las bases de datos y los registros trataron de categorizar elementos medibles para cruzar diferentes aspectos del comercio internacional del petróleo mexicano centrándose en el periodo neoliberal pero tomando el periodo de sustitución de importaciones como antecedente.

La razón que utilizar los registros y bases de datos, así como elegir estos aspectos — creci- 
miento, precios, importación y exportación, reservas, producción y destino - para categorizar las variables fue para tratar de abarcar el mayor espectro posible del comercio petrolero internacional para concluir si el periodo neoliberal fue una política que trajo beneficio - $\mathrm{O}$ no- a la economía mexicana y compararla con la posible política económica del nuevo gobierno. A pesar de que podría ser una conclusión subjetiva por los pocos elementos analizados hasta ahora (septiembre de 2019 a menos de un año de gobierno lopezobradorista) si podría concluirse que las variables son las mismas, por lo que ambos aspectos son medidos bajo las mismas reglas básicas.

\section{Procedimiento}

La investigación pasó por dos periodos: el primero, retomar todos los datos posibles referentes al petróleo en México y, la segunda, construir categorías básicas de medición a partir de los elementos e información disponible en las principales fuentes de información consultadas. Con esta idea básica, los primeros elementos tomados en cuenta fueron las importaciones y exportaciones de crudo y derivados, en cantidad de barriles y dinero, para comprobar el déficit que tiene el país.

Inmediatamente después fue necesario analizar las reservas y la producción de crudo para comprobar qué tan grande ha sido la explotación del recurso así como los beneficios que han devenido con esa explotación. Después de eso, fue necesario conocer cuál es el precio con el que se vende el crudo mexicano en el mercado internacional y compararlo con nuestros principales competidores, seguido de identificar el principal destino de los recursos y las ganancias que recibe PEMEX de esos lugares por concepto de comercio petrolero. Con esto, el estudio fue delimitado en periodos sexenales y la información fue cruzada con la aplicación de políticas de sustitución de importaciones, neoliberalismo e inicio del gobierno de López Obrador, para concluir con los resultados reales de las políticas aplicadas.

\section{4.- RESULTADOS}

El análisis muestra como resultados que la política petrolera aplicada en el periodo neoliberal fue deficiente conforme a las décadas anteriores en las que la política de industrialización por sustitución de importaciones aumentó las reservas y la producción, a pesar de que fue a través de un aumento del endeudamiento que generó - de la mano con muchos otros elementos originados en el escenario internacional- las crisis de las décadas de 1970 y 1980, dando paso al periodo neoliberal.

En ese sentido, la aspiración de la política neoliberal fue minimizar los problemas de crisis y mantener el aumento de las exportaciones aumentando la explotación de las reservas. Sin embargo, conforme la producción y exportación fue en aumento, los precios internacionales disminuyeron resultando, por un lado, en una necesidad cada vez mayor por recursos y, por otro lado, la necesidad de importar productos refinados.

En resumen, el neoliberalismo propició la necesidad de producir cada vez más petróleo para exportar y cada vez más necesidad de productos refinados. Por esa razón, el nuevo periodo pre- 
sidencial del presidente López Obrador buscó minimizar la dependencia de productos refinados importados. Sin embargo, la propuesta no contempla inversión en exploración o en tecnología, por lo que la autosuficiencia no parece probable.

\section{5.- CONCLUSIONES}

El petróleo ha estado en constante cambio en el país desde su aparición hasta las diferentes reformas que se han aplicado bajo argumento de beneficio colectivo. La institucionalización de la revolución, y con esto la adopción del petróleo como elemento de identidad nacional, financió el crecimiento de país a través de las políticas de sustitución de importaciones, creando empresas paraestatales en todos los ámbitos de la productividad nacional y dio paso al "milagro mexicano", que duró hasta las finales de la década de 1970 y que significó un cambio en los manejos económicos del país reflejados en las reformas de 1986 que planteaba la apertura del país en términos económicos, principalmente, pero también en lo político y social.

A partir de ese momento, la clase política mexicana requirió mantener un argumento nacionalista y de corte social para reformar aspectos referentes a la industria petrolera. La apertura económica de finales de la década de 1980 propició que, a nivel discursivo, el gobierno propusiera los cambios requeridos por la industria a partir de los beneficios colectivos que estas reformas traerían. En la primera década del siglo XXI, el discurso planteaba reformar el sector y alargar los beneficios petroleros dando forma a la reforma de 2013. Con esta reforma, el gobierno proponía hacer más eficaz a la industria y cambiar la situación deficitaria de la balanza comercial petrolera. Sin embargo, en los pocos años de aplicación, esos problemas han empeorado por diversos factores coyunturales.

Con el nuevo gobierno de López Obrador, los factores coyunturales del país no ofrecen muestras reales de éxito para las propuestas del presidente López Obrador pues éstas están centradas en gastos de construcción de refinerías, cuando la tendencia global va en sentido contrario, y nula inversión en tecnología y exploración.

\section{REFERENCIAS}

Aguilera Gómez, M. (2015). El petróleo mexicano. Conflicto, esperanza y frustración. Miguel Ángel Porrúa-UNAM-Programa Universitario de Estudios del Desarrollo.

Aguirre Botello, M. (6 de mayo 2018). PEMEX, cronología expropiación y estadística. Méxicomaxico.org. Recuperado de:

http://www.mexicomaxico.org/Voto/pemex.htm

Banco Mundial (2017). Tasa de Crecimiento anual: México. Grupo Banco Mundial. Obtenido de:

http://databank. worldbank.org/data/reports.aspx? source=2\&series=NY.GDP.MKTP. KD.ZG\&country=MEX\# 
Banco de México (2019). Precio de la mezcla mexicana de petróleo. Grupo Banco de México. Obtenido de: https://www.banxico.org.mx/apps/gc/precios-spot-del-petroleo-gra.html

BBC (19 de marzo 2019). AMLO y PEMEX: el polémico plan del presidente en México para rescatar la petrolera de su peor crisis de producción en 40 años. México: BBC News Mundo. Obtenido de: https:/www.bbc.com/mundo/noticias-america-latina-47620358

Brown, J. C. (1993). Oil and Revolution in México. University of California Press.

Cárdenas Gracia, J. (2009). En defensa del petróleo. UNAM.

Cruz Soto, L. A. (2002), Neoliberalismo y globalización. Algunos elementos de análisis para precisar los conceptos. Revista Contaduría y Administración, (205), 13-26.

Cuellar Laureano, R. (2008). El petróleo y la política exterior de México: del auge petrolero a la privatización. Revista de Relaciones Internacionales, (101-102), 121-143.

Expansión (30 de septiembre de 2019). Precio petróleo Brent. Datosmacro.com. Obtenido de: https://datosmacro.expansion.com/materias-primas/brent

Expansión (30 de septiembre de 2019). Precio petróleo tipo West Texas Intermediate (WTI). Datosmacro.com. Obtenido de:

https://datosmacro.expansion.com/materias-primas/petroleo-wti

Freindenberg, F. y Aparicio, F. J. (2016). México 2015: entre la fragmentación partidista y el descontento ciudadano. Revista de Ciencia Política, 36 (1). 219-238.

Garner, P. (2015). El nacimiento de El Águila y la apoteosis del imperio, de 1901 a 1910. La gaceta del Fondo de Cultura Económica. (531), 8-9.

Gutiérrez, R. (2011). Los costos ex post de la reforma energética: una evaluación anticipada del sexenio de Felipe Calderón. Análisis económico, 26. (63), 215-245.

Lajous, R. (2010). La política exterior del porfiriato (1876-1911). En: Blanca Torres (coordinadora). México y el mundo. Historia de sus relaciones exteriores. Vol. IV. COLMEX.

Lomas Maldonado, A. (S/F). El petróleo mexicano, entre la voracidad trasnacional y la sumisión gubernamental, desde 1900 hasta la fecha. AUM-Iztapalapa. (Consultado 2 de febrero de 2017). Recuperado de:

http://www.izt.uam.mx/forospetroleo/pdfs/lomas.pdf

López Obrador, A. M. (2008). La gran tentación. El petróleo de México. Grijalbo.

Meyer, L. (1981). México y Estados Unidos en el conflicto petrolero (1917-1942). COLMEX.

PEMEX (1977). Anuario estadístico de PEMEX, 1978. PEMEX.

PEMEX (1988). Anuario estadístico de PEMEX, 1988. PEMEX.

PEMEX (1990). Anuario estadístico de PEMEX, 1990. PEMEX.

PEMEX (1999). Anuario estadístico de PEMEX, 1999. PEMEX.

PEMEX (2001). Anuario Estadístico de PEMEX, 2001. PEMEX. 
PEMEX (2002). Anuario Estadístico de PEMEX, 2002. PEMEX.

PEMEX (2003). Anuario Estadístico de PEMEX, 2003. PEMEX.

PEMEX (2004). Anuario Estadístico de PEMEX, 2004. PEMEX.

PEMEX (2005). Anuario Estadístico de PEMEX, 2005. PEMEX.

PEMEX (2006). Anuario Estadístico de PEMEX, 2006. PEMEX.

PEMEX (2007). Anuario Estadístico de PEMEX, 2007. PEMEX.

PEMEX (2008). Anuario Estadístico de PEMEX, 2008. PEMEX.

PEMEX (2009). Anuario Estadístico de PEMEX, 2009. PEMEX.

PEMEX (2010). Anuario Estadístico de PEMEX, 2010. PEMEX.

PEMEX (2011). Anuario Estadístico de PEMEX, 2011. PEMEX.

PEMEX (2012). Anuario Estadístico de PEMEX, 2012. PEMEX.

PEMEX (2013). Anuario Estadístico de PEMEX, 2013. PEMEX.

PEMEX (2014). Anuario Estadístico de PEMEX, 2014. PEMEX.

PEMEX (2016). Anuario Estadístico de PEMEX, 2016. PEMEX.

PEMEX (2017). Anuario Estadístico de PEMEX, 2017. PEMEX.

PEMEX (2018). Anuario Estadístico de PEMEX, 2018. PEMEX.

PEMEX (2019). Estadística petrolera. Informe mensual sobre producción y comercio de hidrocarburos. 31 (9). Septiembre de 2019. México. PEMEX. Recuperado de:

https://www.pemex.com/ri/Publicaciones/Indicadores\%20Petroleros/indicador.pdf

PEMEX (2019). Volumen de las exportaciones de petróleo crudo por destino geográfico, Base de Datos Institucional, México, PEMEX, Consultado 1 de octubre de 2019. Recuperado de:

http://ebdi.pemex.com/bdi/bdiController.do?action=cuadro\&cvecua=IVOLXCO

PEMEX (2019). "Valor de las exportaciones de petróleo crudo por destino geográfico", Base de Datos Institucional, México, PEMEX, Consultado 1 de octubre de 2019. Recuperado de:

http://ebdi.pemex.com/bdi/bdiController.do?action=cuadro\&cvecua=IVALXCO

Presidencia de la República (2019), Plan Nacional de Desarrollo, 2019-2024, México,

https://lopezobrador.org.mx/wp-content/uploads/2019/05/PLAN-NACIONAL-DEDESARROLLO-2019-2024.pdf

Revueltas, A. (1996). Las transformaciones del Estado Mexicano: un Neoliberalismo "a la mexicana". UAM-Xochimilco.

Rivas Correa, L. (2009). La nueva era del petróleo en México. PetroQuiMex. La revista de la industria petrolera, 6-10. 
Salinas de Gortari, C. (2008). La década perdida. 1995-2006. Neoliberalismo y populismo en México. RandomHouseMondadori.

Secretaria de Energía (2017). Seguimiento precio del petróleo mezcla mexicana (MME). Servicio Geológico Mexicano. Consultado 10 de marzo de 2017. Rescatado de: http:// portalweb.sgm.gob.mx/economia/es/energeticos/mezcla-mexicana.html

Solís, A. (2019), La apuesta arriesgada de PEMEX, no ir a aguas profundas. Forbes México, 106-108.

The Economist (19 de septiembre de 2019), Why Latin America's left loves the petroleum economy. The Economist Newspaper Limited. Rescatado de:

https:/www.economist.com/the-americas/2019/09/19/why-latin-americas-left-loves-thepetroleum-economy

Uhthoff López, L. M. (2010). La industria del petróleo en México, 1911-1938: Del auge exportador al abastecimiento del mercado interno. Una aproximación a su estudio. América Latina en la historia económica, (33), 5-30. 